\title{
O caminhar da enfermagem em fenomenologia: revisitando a produção acadêmica
}

\author{
The getting under way of the nursing in phenomenology: re visiting the academical production
}

\author{
El camiñar de la enfermería en fenomenología: revisitando la producción académica
}

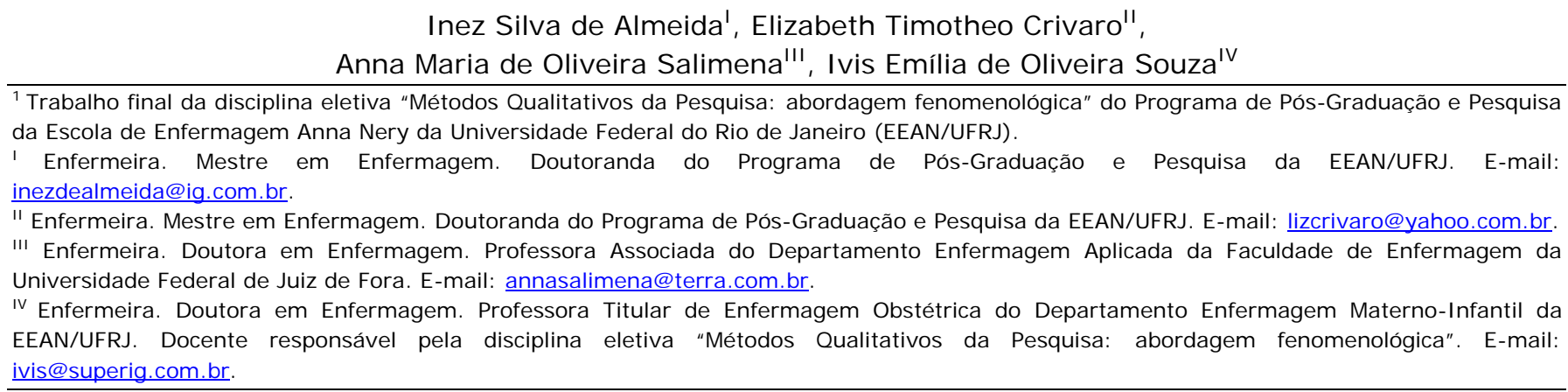

\section{RESUMO}

Este artigo trata da apropriação do referencial da Fenomenologia na pesquisa acadêmica de Enfermagem. Teve como objetivo geral analisar a utilização do referencial fenomenológico nas pesquisas da enfermagem, e como objetivos específicos: caracterizar a produção acadêmica de enfermagem sustentada na abordagem fenomenológica; destacar os referenciais teóricos mais utilizados na produção acadêmica da enfermagem; correlacionar as áreas do cuidar de enfermagem à luz dos referenciais teóricos. É um estudo de revisão no qual verificamos a produção científica de 1987 a 2007, do banco de teses da Coordenação de Aperfeiçoamento de Estudos de Nível Superior. Identificamos a presença de trezentos e cinqüenta e nove estudos, entre dissertações e teses. As pesquisas fundamentam-se principalmente na abordagem de Martin Heidegger, Alfred Schutz e Merleau-Ponty. Observamos que foram mais evidenciadas as áreas dos estudos que envolvem os enfermeiros e/ ou equipe, docentes e discentes e a área da saúde do adulto/idoso. Concluímos que utilizando o referencial fenomenológico, os enfermeiros-pesquisadores podem dar voz ao Homem e visibilidade aos fenômenos por ele vividos.

Descritores: Enfermagem; Pesquisa em Enfermagem; Pesquisa Qualitativa.

\section{ABSTRACT}

This article deals with the appropriation of the referencial of the Fenomenologia in the academic research of Nursing. The general study objective was analyse the use of the phenomenological reference in the nursing researches, and as specific objectives: characterize the nursing academic production maintained in the phenomenological approach; emphasize the theoretical references more used in the nursing academic production; correlate the nursing care areas by the light of the theoretical references. The study allowed us to verify the scientific production from 1987 to 2007 , of the thesis bank of the Coordenação de Aperfeiçoamento de Estudos de Nível Superior (" Coordination of Superior Level Studies Improvement"). Among the abstracts found through the use of the phenomenological reference in the Nursing researches, we identify the presence of three hundred and fifty and nine studies, including dissertations and thesis. The researches found were based on the Martin Heidegger's, Alfred Schultz's and Merleau-Ponty's approach. In our analysis, we observed that were more evidenced the studies areas that include the nurses and / or / team, teaching body and student body and the woman health area. We concluded that using the phenomenological reference, the nurses - researches can tell the Man he can speak and visibility to the phenomenona experienced by him.

Descriptors: Nursing; Nursing research; Qualitative Research.

\section{RESUMEN}

Este artículo se ocupa de la apropiación del referencial del Fenomenologia en la investigación académica de la enfermería. El objetivo general fue analizar la utilización del referencial fenomenológico en las investigaciones de la enfermería, y como objetivos específicos: caracterizar la producción académica de la enfermería sustentada en el abordaje fenomenológico; destacar los referenciales teóricos mas utilizados en la producción académica; correlacionar las áreas del cuidar en enfermería a la luz de los referenciales teóricos. El estudio nos permitió verificar la producción científica de 1987 a 2007, del banco de tesis de la Coordinación de perfeccionamiento de Estudios de Nivel Superior. Entre los resúmenes encontrados utilizando el referencial fenomenológico en las investigaciones de la Enfermería, identificamos la presencia de trescientos y cincuenta y nueve estudios, incluyendo disertaciones y tesis. Las investigaciones encontradas se fundamentaban en el abordaje de Martin Heidegger, seguido por Alfred Schutz y Merleau-Ponty. En nuestro análisis, observamos que fueron mas evidenciadas las áreas de los estudios que envuelven los enfermeros y/o equipo, docentes y discentes y el área de la salud de la mujer. Concluimos que utilizando el referencial fenomenológico, los enfermeros investigadores pueden dar voz al Hombre y visibilidad a los fenómenos por él vividos, posibilitando, ofrecerle un cuidar a partir de su singularidad. 
Descriptores: Enfermería; Investigación en Enfermería; Investigación Cualitativa. 


\section{CONSI DERAÇÕES I NI CI AIS}

A Enfermagem como atividade humana existe há muitos anos, embora sejam considerados como profissão jovem. Expressando-se como atividade profissional, vem se estabelecendo e se desenvolvendo a partir da construção e da consolidação do seu saber, à medida que utiliza a pesquisa como instrumento do conhecimento teóricoprático, como desafio para a transformação(1).

Inicialmente evoluiu em direção à cientificidade seguindo os caminhos da ciência dita positiva. Nesse seu trajeto em busca do crescimento científico, a enfermagem se inspirou no modelo tradicional biomédico das ciências naturais e exatas calcado no método experimental. $\mathrm{O}$ modelo biomédico obedece às exigências da corrente de pensamento denominada Positivismo, que só aceita como conhecimento aquele decorrente da experimentação, além de oferecer uma explicação dos fatos. As pesquisas e análises que favoreceram a sistematização de um saber específico da enfermagem com características positivistas, valorizando o concreto, o palpável, o comparável, foram a tônica da formação profissional no modelo nightingaleano. Esta forma de pensar e fazer pesquisa influenciou de forma decisiva a prática da enfermagem ${ }^{(2)}$.

A profissão passou de um fazer empírico e assistemático para uma prática tecnicista voltada para o objetivo, para os resultados, para o fim em si mesmo, mediante a realização de procedimentos baseados na elaboração/implementação de planos de cuidados. Nesta perspectiva, o avanço científico levou a enfermagem a sofrer profundas modificações, que se caracterizaram principalmente pela fragmentação e pela compartimentalização do seu agir/cuidar, bem como pela estratificação de categorias em diversos agentes (enfermeiro, técnico de enfermagem e auxiliar de enfermagem), cada um realizando uma atividade parcelada dentro das especialidades da área de enfermagem no campo da saúde ${ }^{(3)}$.

Como consequências lógicas dessa fragmentação surgiram e se impuseram de forma efetiva as regras, rotinas, normas e regulamentos, que acabaram por massificar, generalizar e padronizar o cuidado de enfermagem. Mais do que isso, esse cuidado se tornou de tal modo impessoal, que obscureceu o olhar direcionado a pessoa a quem deveria ser dedicado: o homem, perdendo a visão do todo e da integralidade do ser do humano(2)

A sofisticada tecnologia, os aparatos mecânicos colocaram o Homem em segundo plano, quando do cuidar da enfermagem ${ }^{(2)}$. Entretanto, o cuidar sempre esteve presente na vida e na história do Homem e é anterior à sua expressão na enfermagem $^{(3)}$.

Após um período de intensa qualificação profissional, em busca do saber técnico-científico e tecnológico (mediante os cursos de pós-graduação lato sensu, iniciados na segunda metade do século passado, no Brasil), a enfermagem voltou-se mais diretamente ao seu semelhante, ao perceber que o seu diferencial se localiza no cuidar humano ${ }^{(4)}$.

O cuidado se originou do interesse, preocupação e afeto e é relacionado à Enfermagem pela associação da mulher ao maternal e educar, voltando-se ao crescimento do indivíduo. A partir das práticas do cuidar materno, surgimento e a ameaça de doença, a mulher se investiu do papel de cuidadora e desenvolveu ações de bem-estar e restabelecimento. Com o passar do tempo, dedicouse às atividades de conforto e minimização do sofrimento ${ }^{(5)}$.

A enfermagem foi em busca do cuidar efetivo, implementando o cuidado em seu cotidiano como forma de relacionar-se, como compromisso, responsabilidade, zelo. Cuidar envolve olhar o outro, estabelecer condições para que o outro cresça, estar disponível para vê-lo e ouvi-lo, com a finalidade de confortar, aliviar, proteger ${ }^{(5)}$.

Em meados da década de 80 foi iniciada uma nova fase na enfermagem, na qual as enfermeiras começaram a se aproximar da pesquisa qualitativa, distanciando-se da abordagem quantitativa. Deixaram, portanto, de valorizar apenas os aspectos técnicos do cuidado e se voltaram para a compreensão dos sujeitos envolvidos no processo cuidar-cuidado. Esse movimento se solidificou, expandindo-se internacionalmente ${ }^{(4,6)}$.

À medida que a enfermagem buscou compreender o ser em sua dimensão holística, abriu o cenário de possibilidades do cuidado do outro em sua integralidade. Ao lidar com questões existenciais dos seres de quem cuida, apropriou-se da fenomenologia como suporte para suas reflexões e sua prática, numa imersão na subjetividade e na essência que permeia o cuidar $^{(7)}$.

A pesquisa fenomenológica na enfermagem aponta para os fenômenos adoecer, morrer, relacionar-se com o outro, fenômenos estes que não podem ser compreendidos isolados da pessoa que os vivencia na totalidade de sua existência. Ou seja, é preciso compreender o fenômeno a partir do ser que o vivencia, dentro do contexto de seu existir ${ }^{(8)}$.

Para ampliar a compreensão do pensar e do fazer, pesquisadores-enfermeiros passaram a procurar desenvolver pesquisas, principalmente dissertações e teses, segundo a abordagem fenomenológica de pesquisa.

Nessa linha, este estudo pretende, a partir de uma revisão acerca da produção acadêmica, responder à seguinte questão: Como a fenomenologia tem sido utilizada nas pesquisas da enfermagem? Nosso questionamento se justifica na crença de ser de grande valor analisar as produções acadêmicas de enfermagem construídas, tendo como 
base teórico-metodológica a fenomenologia.

Diante do exposto, elegemos como objeto do presente estudo, a produção acadêmica de enfermagem desenvolvida segundo a abordagem fenomenológica. Neste sentido, destacamos como objetivo geral: analisar a utilização do referencial fenomenológico nas pesquisas em enfermagem, e como objetivos específicos: caracterizar a produção acadêmica de enfermagem segundo o referencial filosófico; identificar os referenciais teóricos da fenomenologia mais utilizada na produção acadêmica de enfermagem, destacar as categorias temáticas e correlacioná-las aos referenciais teóricos.

\section{A Enfermagem e a Fenomenologia}

As raízes da pesquisa em Enfermagem utilizaram o modelo biomédico e a abordagem quantitativa, pautados numa concepção Positivista, que não contemplava os aspectos subjetivos do cotidiano associado aos seus dilemas existenciais. Esse modelo, embora hegemônico, passou a concorrer com outros, em decorrência principalmente de sua incapacidade para abranger toda a multiplicidade de fatores que interferem no processo de saúde do ser humano(9).

Ocorreu, então, na Enfermagem, a busca de um método de investigação que abarcasse seu modo de ser, enquanto ciência e arte. Questões referentes ao sentido da vida e seus significados merecem o olhar cuidadoso de um referencial que contemple no cotidiano assistencial aspectos não - quantificáveis na pesquisa.

Nesse sentido, o caminhar em direção à pesquisa qualitativa refletiu um movimento da Enfermagem ao se voltar para influências filosóficas como a Fenomenologia, mais adequada à busca de compreensão e explicação dos fenômenos sociais, fazendo emergir novas abordagens metodológicas nas investigações científicas ${ }^{(10)}$.

Esta corrente de pensamento mostrou a potencialidade de um referencial metodológico que se apresenta como alternativa para conhecer o universo mais profundo da vivência humana, a qual é a Fenomenologia(11)

A Fenomenologia nasceu na Alemanha no final do século $X X$ em posição antagônica ao conhecimento científico tradicional. Esta ciência buscava a compreensão do ser humano, sua consciência, sua liberdade, sua dimensão ética e valorativa, numa tentativa de preencher a lacuna não preenchida pelo Positivismo que abordava somente questões da ciência relacionadas à lógica e à precisão(11).

Desenvolvida por Husserl, a Fenomenologia, ciência eidética, rigorosa, descritiva, não dedutiva, preocupa-se em mostrar o fenômeno na sua essência, permitindo que se mostre como realmente é, através da descrição da experiência vivida ${ }^{(7)}$.

Assim, a preocupação da Fenomenologia é descrever o fenômeno e não explicá-lo, compreendêlo sem a preocupação de identificar as relações de causa e efeito, descrever o fenômeno direcionando o olhar para análise do vivido buscando nas situações vivenciadas, compreender sem interferir na sua originalidade $^{(11)}$

Ao buscar a compreensão do significado da experiência vivida dos seres humanos, essa abordagem tem trazido contribuições valiosas para o conhecimento das múltiplas dimensões que envolvem o cuidado no processo de viver humano, até então inexploradas ${ }^{(7)}$.

A visão do fenômeno saúde não limitada às causas e aos sintomas, pode ser traduzida através do método fenomenológico, ampliando-o para uma perspectiva multifacetada mediante os diversos fatores, de ordem econômica, política, social, psicológica e cultural, com os quais se interrelaciona ${ }^{(12)}$.

Dessa forma, as pesquisas de enfermagem pautadas na Fenomenologia buscam compreender o ser humano na sua interação com o mundo, lançando mão das descrições. A descrição rigorosa do fenômeno articulada ao discurso do sujeito é que permite chegar à sua essência, desvelando-o ${ }^{(12)}$.

Essa forma de fazer ciência possibilitou observar que existe um sujeito antes da realidade objetiva( ${ }^{(8)}$. A reflexão fenomenológica, voltada para a experiência vivida, inclui a possibilidade de olhar as coisas como elas se manifestam ${ }^{(9)}$. Esse mundo experienciado/vivenciado se abre e se desvela para o homem. Ao se voltar para as coisas mesmas e para o mundo vivido, objetivando apreender a essência do fenômeno, emerge a possibilidade de cuidar do outro a partir das demandas próprias a ele, sem determinações prévias e sem pressupostos ${ }^{(11)}$.

A abordagem fenomenológica passou a despertar a atenção de pesquisadores de Enfermagem como um método alternativo de investigação em substituição aos métodos tradicionais utilizados pelas ciências naturais. Analisando esta perspectiva de pensar a realidade e aproximando-a da Enfermagem, observamos que ela contempla as inquietações de quem centra o foco do seu cuidar no ser humano. Embora os grandes filósofos não tenham elaborado aspectos específicos para a Enfermagem, eles abordaram questões de interesse para a profissão, captando uma mensagem através do olhar cuidadoso e transcrevendo-a para uma análise compreensiva posterior ${ }^{(7-8)}$.

\section{TRAJ ETÓRI A DO ESTUDO}

Esta pesquisa de natureza bibliográfica se apropriou do conhecimento, por meio da investigação dos resumos que foram publicados no portal da Fundação Coordenação de Aperfeiçoamento de Pessoal de Nível Superior do Ministério da Educação e Cultura (CAPES). Segundo Lakatos, a pesquisa 
bibliográfica, além de se apropriar do conhecimento pré-existente, promove uma maior aproximação acerca dos conhecimentos sobre determinado tema com novo enfoque, possibilitando ao pesquisador chegar a conclusões inovadoras ${ }^{(13)}$.

Como fonte primária de dados, pesquisamos o Banco de Teses da CAPES. Essa base de dados disponibiliza resumos relativos a dissertações e teses defendidas a partir de 1987. No momento seus registros vão até o ano de $2007^{(14)}$.

A técnica utilizada para captação dos dados foi definida através do site de busca do banco de teses, no qual elegemos como palavra-chave "fenomenologia", realizando separadamente a pesquisa dos resumos de Mestrado dos resumos de Doutorado.

Ao evidenciarmos as páginas com os títulos dos diversos estudos, selecionamos os referentes à Enfermagem e fizemos uma compilação dos mesmos. O material empírico foi organizado a partir da criação de um instrumento que incluía: título, instituição, ano de publicação e referencial teórico, o que possibilitou a sistematização e posterior análise dos dados. Dessa forma catalogamos as produções acadêmicas que utilizaram como caminho metodológico, a abordagem fenomenológica, no período de 1987 a 2007 e destacamos os referenciais teóricos mais utilizados.

As produções foram quantificadas e os resumos foram submetidos à técnica de análise de conteúdo, na modalidade temática, na qual entendemos o tema como a unidade de significação que emerge do material analisado(15).

Os resumos foram lidos e o discurso dos documentos definido, demarcando o corpus da pesquisa. Ainda nesse momento os mesmos foram organizados em quadros e tabelas com o objetivo de tornar mais clara à visualização dos dados, estabelecendo a análise descritiva.

A análise de conteúdo é uma proposta teóricometodológica que compreende iniciativas de explicitação, sistematização e expressão do conteúdo de mensagens, com a finalidade de efetuar deduções lógicas e justificadas a respeito destas mensagens, quem as emitiu, em que contexto e/ou quais efeitos se pretende causar por meio delas ${ }^{(15)}$.

Após, a organização dos resumos em categorias direcionou o processo de interpretação. Para, Ludke e André a produção de categorias não segue um conjunto padronizado de regras, sendo importante observar os principais temas, comentários e idéias que aparecem mais freqüentemente, e que reflitam os objetivos da pesquisa(16).

Assim emergiram as categorias da área do cuidar: saúde da mulher, da criança, do adolescente, do adulto/idoso e os estudos que abordavam na sua temática o profissional de enfermagem (enfermeiros e/ ou equipe, docentes e discentes).

\section{RESULTADOS E DISCUSSÃO}

A partir do acesso ao banco de dados, foi possível evidenciar 2955 resumos no total, encontrados nas diversas áreas de saber envolvendo a abordagem fenomenológica. Desses, 359 envolvendo a abordagem fenomenológica foram produzidos por enfermeiras. Vale ressaltar que desse total seis trabalhos não foram considerados, por não ter sido possível, a partir de suas temáticas, categorizá-los.

Ao analisar os resumos observamos uma variedade de teóricos e em um mesmo trabalho a associação de mais de um teórico, nem sempre relativo à corrente filosófica da fenomenologia, para dar sustentação ao estudo, apontando assim, para outras possibilidades de compreensão. Nessa perspectiva ao compreender que a Fenomenologia estuda a descrição dos fenômenos humanos e seus significados, a produção da Enfermagem neste campo se mostra no caminho da crítica, da reflexão, e da busca de significados essenciais para a compreensão de seu fazer apoiando-se nos diversos teóricos.

No que tange aos dados acima representados, chama a atenção o número significativo de produções em que o teórico não foi referendado. Esses resultados nos levam a refletir criticamente sobre a qualidade dos resumos enviados para o portal CAPES, já que podem subsidiar novos estudos.

Ao correlacionar os teóricos e as categorias da área do cuidar, observamos que as pesquisas pautadas em Martin Heidegger foram as mais evidenciadas nos estudos que envolvem os enfermeiros e/ ou equipe, docentes e discentes com trinta estudos e a área da saúde da mulher com vinte e nove.

Ressaltamos que a natureza da abordagem iluminada pelo pensar de Martin Heidegger, ao buscar na singularidade a compreensão do ser-aí que cuida e é cuidado justifica a relevância da sua utilização nas referidas áreas ${ }^{(10)}$. "Novos caminhos são abertos para se aproximar, cuidar e resolver problemas humanos vitais $(\ldots)$. Problemas de assistência terapêutica a grupos (...), enfim, inúmeros problemas de atividades humanas podem ser compreendidos através de novos horizontes abertos através da maneira pela qual Heidegger nos ensina a pensar"(17).

Observamos que as pesquisas fenomenológicas têm enfocado predominantemente os estudos voltados aos enfermeiros, docentes e discentes. Isto indica uma preocupação em privilegiar a escuta e o olhar do profissional. A enfermagem enquanto prática social de atenção à saúde que lida diretamente com o ser humano e toda a sua complexidade necessita vislumbrar a prática do cuidador por meio da investigação voltada para uma escuta sensível, solidária e acolhedora fomentando saberes. Nesse sentido se apropriar de uma abordagem humanística 
abre perspectivas de cuidar pautada na reflexão e na compreensão(10).

Ao mapear as produções, em ordem decrescente, os referenciais filosóficos mais utilizados foram de Martin Heidegger, Alfred Schutz e Maurice Merleau Ponty.

Esses teóricos foram associados a outros, para também iluminar as pesquisas de enfermagem e Merleau Ponty foi o mais utilizado nessas associações seguido de Martin Heidegger e Alfred Schutz (Tabela $1)$. 


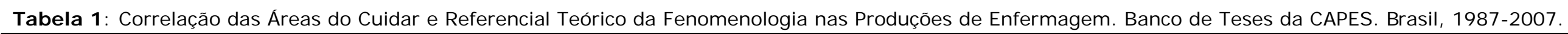

\begin{tabular}{|c|c|c|c|c|c|c|c|}
\hline \multirow{2}{*}{ Ref. Teórico } & \multicolumn{7}{|c|}{ Categorias } \\
\hline & $\begin{array}{c}\text { Enfermeiros / Docentes / } \\
\text { Discentes }\end{array}$ & $\begin{array}{l}\text { Saúde Adulto / } \\
\text { I doso }\end{array}$ & $\begin{array}{l}\text { Saúde } \\
\text { Mulher }\end{array}$ & $\begin{array}{c}\text { Saúde } \\
\text { Adolescente }\end{array}$ & $\begin{array}{l}\text { Saúde } \\
\text { Criança }\end{array}$ & $\begin{array}{l}\text { Cuidadores / } \\
\text { Família }\end{array}$ & Total \\
\hline Não referido & 55 & 31 & 23 & 05 & 02 & - & 116 \\
\hline Alfred Schutz & 22 & 11 & 07 & 07 & 05 & 07 & 59 \\
\hline Merleau Ponty & 11 & 09 & 09 & 05 & 01 & - & 35 \\
\hline Martins e Bicudo & 06 & - & 02 & 02 & - & 01 & 11 \\
\hline Paterson e Zderad & 03 & 01 & - & - & 01 & 01 & 06 \\
\hline Victor Frankl & 02 & 01 & - & - & 01 & - & 04 \\
\hline Joel Martins & 03 & - & - & - & - & - & 03 \\
\hline Ricoeur/Motta e Crossetti & 02 & - & & - & - & 01 & 03 \\
\hline Jean Watson & - & - & 01 & - & 01 & - & 02 \\
\hline Giorgi & 02 & - & - & - & - & - & 02 \\
\hline Paul Ricoeur e Martin Heidegger & - & 01 & - & - & - & - & 01 \\
\hline Kübler-Ross & - & 01 & - & - & - & - & 01 \\
\hline Merleau Ponty, Giorgi e Comiotto & 01 & - & - & - & - & - & 01 \\
\hline Martha E. Rogers & - & 01 & - & - & - & - & 01 \\
\hline Merleau Ponty e Maffesoli & - & 01 & - & - & - & - & 01 \\
\hline $\begin{array}{l}\text { Martin Heidegger, Merleau Ponty, } \\
\text { Levinas e Ricoeur }\end{array}$ & - & - & - & - & 01 & - & 01 \\
\hline Connie Zweigg & - & - & 01 & - & - & - & 01 \\
\hline Simone de Beauvoir & - & - & - & 01 & - & - & 01 \\
\hline Paul Ricoeur & 01 & - & - & - & - & - & 01 \\
\hline Luigi Biraghi & 01 & - & - & - & - & - & 01 \\
\hline Jean Watson e Paul Ricoeur & 01 & - & - & - & - & - & 01 \\
\hline Merleau Ponty e Ricoeur & 01 & - & - & & - & - & 01 \\
\hline Giorgi e Roy & - & - & - & 01 & - & - & 01 \\
\hline Alfred Schutz Martins e Bicudo & - & - & - & 01 & - & - & 01 \\
\hline Norman Denzim e Paul Ricoeur & - & 01 & - & - & - & - & 01 \\
\hline $\begin{array}{l}\text { Giorgi, Martins, Bicudo, Forghieri e } \\
\text { Valle }\end{array}$ & - & - & - & - & - & 01 & 01 \\
\hline
\end{tabular}

Fonte: Resumos de Teses e Dissertações publicadas no Portal CAPES 1987-2007 
Percebemos que, sob o enfoque desses autores, ao desvendar as singularidades do ser humano, ao conceber suas ações e relações no contexto da saúde e ao desvelar os significados pela mediação das expressões corporais, a Enfermagem instaura a atitude dialogal, o encontro permeado pela subjetividade e a interação, num processo de busca de compreensão do outro.

Assim, a Fenomenologia e seus pressupostos filosóficos embasam a apreensão do sentido do ser e revela-se um referencial metodológico plausível de ser utilizado pela Enfermagem em seus modos de agir-cuidar e em suas relações homem-homem e homem-mundo.

As pesquisas em enfermagem têm se valido da Fenomenologia como método ou como referencial filosófico, para as mais diversas problemáticas. Então, partindo da premissa que a Fenomenologia tanto é uma abordagem teórica quanto um método de acesso dos fenômenos vividos e vivenciados, compreende-se que esta perspectiva viabiliza o estudo do homem em sua totalidade existencial. Assim permite indagar o sentido inerente à essência, necessitando ir além do que se mostra a partir do pensamento de vários filósofos que sustentam estas investigações, como pode ser apreciado no Gráfico 1. Mas, dentre estes pensadores, Heidegger se destaca como referencial teórico-metodológico nas pesquisas realizadas, visto que trata do compromisso de ir em busca da possibilidade de compreensão da instância fundante do comportamento humano.

Gráfico 1: Teóricos da Fenomenologia mais utilizados pela Enfermagem na Produção acadêmica. Banco de Teses da CAPES. Brasil, 1987-2007.

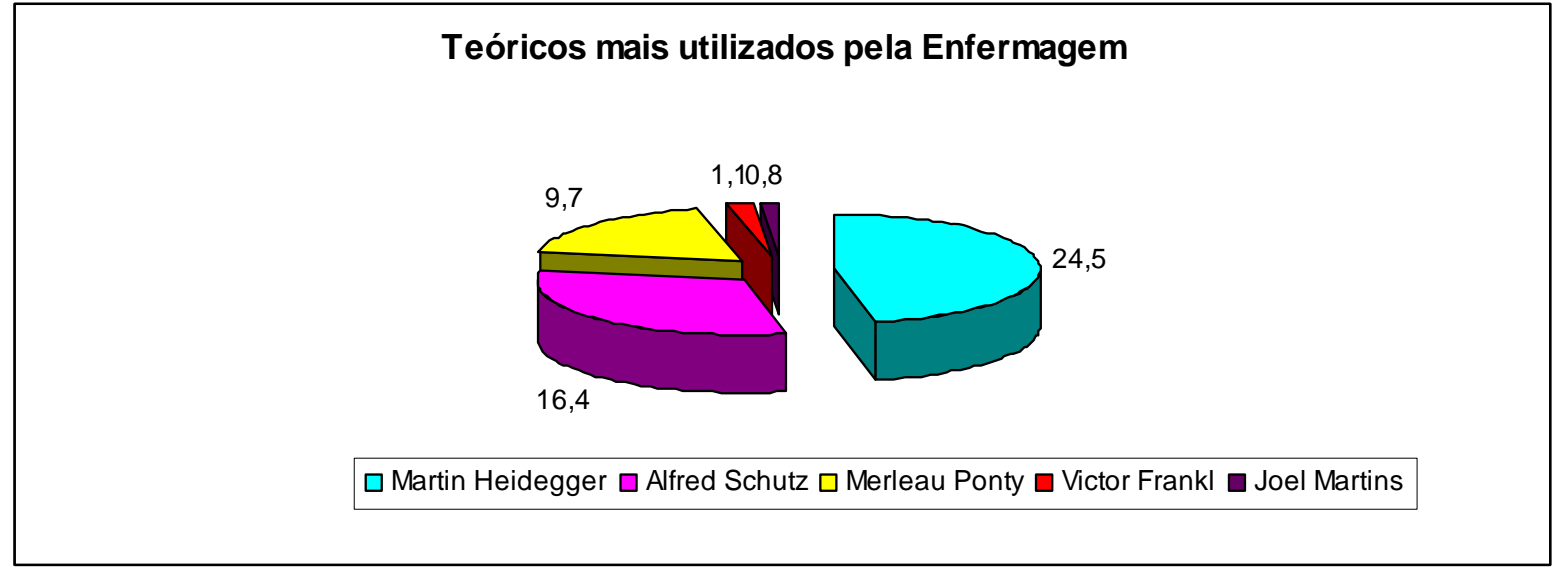

Fonte: Resumos de Teses e Dissertações publicadas no Portal CAPES 1987-2007

Portanto, no fenômeno cuidar em saúde é necessário alcançar à compreensão da essência do humano como ele é, a partir dos significados, que expressa em palavras verbais e/ou escritas, gestos, atitudes e silêncio diante das situações vivenciadas. Sendo assim, busca-se o sentido que funda o comportamento do indivíduo quando ele vive, ama, adoece e é finito ${ }^{(18)}$

Dessa forma, considerando o homem e sua existência, a busca da Enfermagem pela abordagem fenomenológica nas pesquisas aponta em direção das questões que envolvem a complexidade do ser e a compreensão do seu vivido.

Gráfico 2: Produção acadêmica da Enfermagem em Fenomenologia por instituições.

Banco de Teses da CAPES. Brasil, 1987-2007.

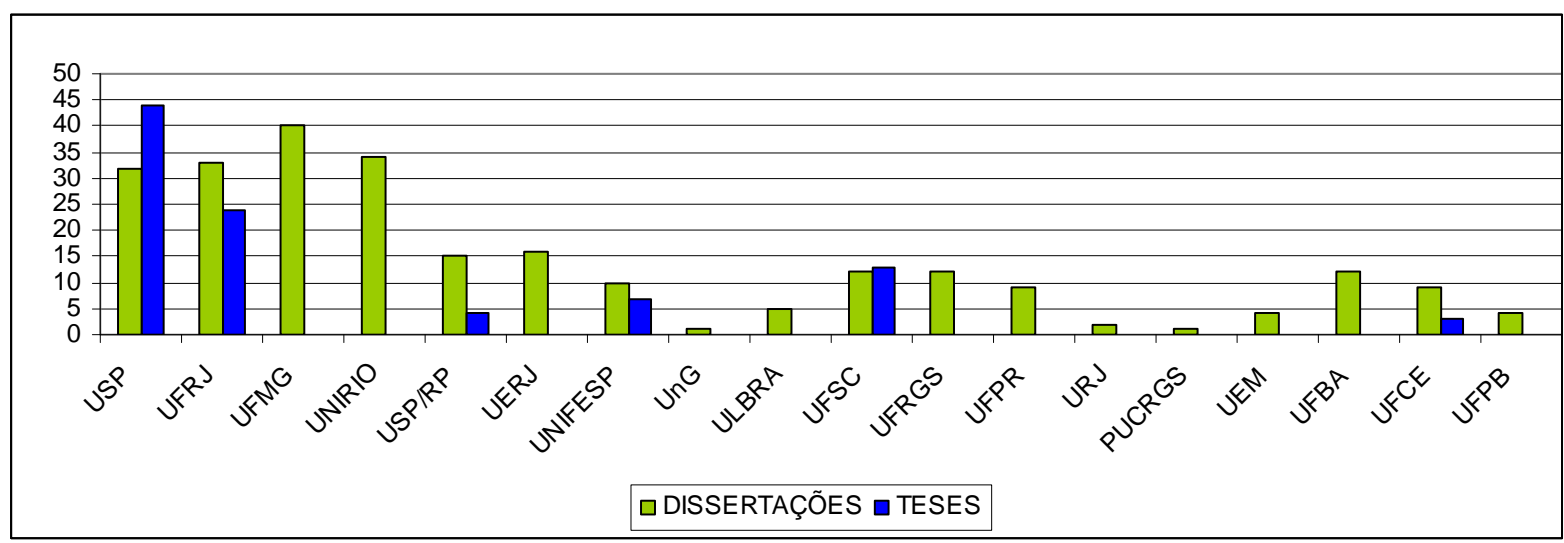

Fonte: Resumos de Teses e Dissertações publicadas no Portal CAPES 1987-2007 
Verificamos que em diferentes programas de pós-graduação do país, um número significativo de dissertações e teses tem procurado fundamentação teórico-filosófica e metodológica no referencial da fenomenologia. Os enfermeiros-pesquisadores que se apropriaram do uso da Fenomenologia como caminho metodológico se destacaram nas instituições da Região Sudeste totalizando 263 estudos. Nessa região, considerando dissertações e teses defendidas, sobressaiu-se a Universidade de São Paulo (USP) com 76 produções e a Universidade Federal do Rio de Janeiro (UFRJ) com 57. Este aspecto reforça o pioneirismo e o compromisso destas duas universidades públicas com a qualificação da carreira acadêmica na área Enfermagem.

A construção de conhecimentos tem sido uma preocupação constante na trajetória evolutiva da história da enfermagem mundial, evidenciada nos últimos trinta anos, com a implementação dos cursos de pós-graduação ${ }^{(10)}$.

Os cursos de pós-graduação Stricto Sensu (mestrado e doutorado) surgiram a partir de 1972, com o curso de Mestrado da Escola de Enfermagem Anna Nery e num processo evolutivo, o primeiro programa de Doutorado em Enfermagem foi criado em 1981 pelas Escolas de Enfermagem da Universidade de São Paulo(13).

Compreendemos que nessa região se concentra uma maior oferta de cursos e programas de pósgraduação, ampliando as possibilidades de realização de pesquisas. Nessa perspectiva, muitos pesquisadores se deslocam para a região sudeste, no sentido de buscarem a consolidação de seus conhecimentos e saberes ${ }^{(19)}$.

Essa preocupação reflete o empenho dos enfermeiros em desenvolver sua produção acadêmica para enfrentar os desafios impostos pelas transformações científicas, tecnológicas e políticas do mundo contemporâneo ${ }^{(12)}$.

A pesquisa é ferramenta indispensável no processo de trabalho do enfermeiro, constituindo-se como estratégia essencial para a geração de saberes. $\mathrm{Na}$ área da Enfermagem, as ações de intervenção devem ser norteadas pelas demandas da clientela, o que é possível se vislumbrar por meio da pesquisa, que permite construir uma base de conhecimento cientificamente validado na prática, além garantir a qualidade do cuidado e a credibilidade profissional $^{(20)}$.

\section{CONSI DERAÇÕES FINAIS}

A guisa de conclusão, nos permitimos apresentar e ressaltar alguns aspectos. A valorização da abordagem filosófica existencial de Martin Heidegger, pelos pesquisadores da área de enfermagem, reafirma que estes profissionais vêm buscando desvelar as obscuridades do cuidar para ampliar as possibilidades do olhar ao ser humano como um todo holístico, abandonando o modelo cartesiano, reducionista e de fragmentação do ser humano.

Outro aspecto que acreditamos estar respaldado em nosso estudo, diz respeito ao referencial filosófico de Joel Martins, que apesar de ser uma referência nacional, ainda está sendo pouco utilizada.

A região sudeste se destaca em sua produção científica da enfermagem em fenomenologia, certamente impulsionada pelas Universidades de São Paulo e Federal do Rio de Janeiro. A escassez de pesquisas observadas nas outras regiões interfere e dificulta o fomento de conhecimentos e saberes que possibilitam o aperfeiçoamento evolutivo do profissional. Compreendemos ser fundamental, possibilitar o incremento de pesquisas nas referidas regiões, a fim de favorecer o desenvolvimento da profissão, sem o qual não seria possível a evolução de um cuidar consciencioso e humano.

Nossos resultados também podem levar a uma reflexão crítica sobre a importância da qualidade dos resumos publicados no banco de teses da Coordenação de Aperfeiçoamento de Estudos de Nível Superior.

O conhecimento produzido necessita ser transmitido com o objetivo de levar o profissional a pensar e a perceber as coisas com um outro olhar. Uma das formas de se transmitir os conhecimentos é por meio da divulgação científica, pois quando este não é divulgado impossibilita a aplicação, a crítica e a geração de novos conhecimentos. O conhecimento científico de enfermagem fornece um sustentáculo para o exercício do cuidar, além de oferecer subsídios para uma intensa reflexão sobre a prática, o que traz recursos para a construção de novos paradigmas.

A investigação fenomenológica em seus pressupostos teórico-filosóficos possibilita a análise e compreensão de estudos da enfermagem no contexto da saúde ao buscar compreender o homem em suas múltiplas facetas, em suas vivências, experiências e relações com o mundo cotidiano, ao desvelar o fenômeno vivido em sua essência.

De posse dessas informações, salientamos que, embora o número de publicações tenha atualmente uma quantidade expressiva, ainda carece de aprofundamento e de ampliação para o progresso contínuo da profissão Enfermagem. Assim, ressaltamos que a partir de sua projeção, a Fenomenologia como caminho metodológico, tem tido um crescimento progressivo, sendo uma possibilidade real de compreender o sujeito, à medida que atende a visão do ser humano como um todo holístico. Utilizando o referencial fenomenológico os enfermeiros-pesquisadores podem dar voz ao ser do humano e visibilidade aos fenômenos por ele vividos, possibilitando, portanto oferecer-Ihe um cuidar a partir de sua singularidade. 


\section{REFERÊNCI AS}

1. Assunção AN, Hermes CA, Bernardi G, J ost MT, Theisen TR. Resgate da produção científica do curso de enfermagem da Universidade de Santa Cruz do Sul desde sua fundação. Revista Técnico-científica de Enfermagem. 2003; 1(4): 279-84.

2. Carvalho MDB, Valle ERM. A pesquisa fenomenológica e a enfermagem. Acta Scientiarum. Health Science. 2002;24(3):843-47.

3. Waldow VR. Atualização do cuidar. Aquichan [Internet]. 2008 [ cited 2009 abr 22]; 8 (1): 85-96. Available from: http://aquichan.unisabana.edu.co/index.php/aquicha n/article/view/1596/3384

4. Camargo TC, Souza IEO. A pesquisa em enfermagem no Instituto Nacional de Câncer: trajetória, tendências e perspectivas. Revista Brasileira de Cancerologia. 2003; 49(3): 159-66.

5. Waldow VR. Cuidado Humano: O Resgate Necessário. Porto Alegre: Sagra Luzzatto; 1999.

6. Crivaro ET, Almeida IS, Souza IEO. O Cuidar Humano: articulando a produção acadêmica de enfermagem ao cuidado e ao cuidador. Rev. enferm. UERJ . 2007; 15(2): 248-54.

7. Terra MG, Silva LC, Camponogara S, Kotzias E, Santos A, Souza AlJ et al.Na trilha da fenomenologia: um caminho para a pesquisa em enfermagem. Texto contexto-enferm. 2006; 15(4):672-8.

8. Capalbo C. Considerações sobre o Método Fenomenológico e a Enfermagem. Rev. Enferm. UERJ . 1994; 2(2): 192-97.

9. Gil AC, Licht RHG, Santos BRMS. Por que fazer pesquisa qualitativa em saúde? Caderno de Pesquisa em Ciências da Saúde. 2006; 1(2):5-19.

10. Souto CMRM, Pessoa SMF, Damasceno MMC, Araújo TL. Tendências das pesquisas de enfermagem em saúde da mulher no período de 2001 a 2005. Texto contexto-enferm. 2007; 16(4):719-26.

11. Capalbo C. Fenomenologia e Ciências Humanas. Aparecida: Idéias e letras; 2008.

12. Gomes AMA, Paiva ES, Valdés MTM, Frota MA, Albuquerque CM. Fenomenologia, humanização e promoção da saúde: uma proposta de articulação. Saúde soc. 2008; 17(1)143-52.

13. Lakatos EM, Marconi MA. Técnicas de Pesquisa: Planejamento e execução de pesquisas; Amostragens e técnicas de pesquisa; Elaboração, análise e interpretação de dados. 6th ed. São Paulo: Atlas; 2006.

14. Coordenação de Aperfeiçoamento de Pessoal de Nível Superior [Internet]. Brasília. Ministério da Educação (BR) [cited 2009 Abr 22]. Banco de Teses. Available from: http://www. capes.gov. br/servicos/banco-de-teses.

15. Bardin L. Análise de Conteúdo. Lisboa: Edições 70; 1977.

16. Ludke $M$, André $M$. Pesquisa em educação: abordagens qualitativas. São Paulo: EPU; 1986.
17. Spanoudis S. Apresentação: a todos que procuram o próprio caminho. In: Heidegger M. Todos Nós... Ninguém: Um Enfoque Fenomenológico do Social. São Paulo: Moraes; 1981.

18. Salimena, AMO, Souza, IEO. O sentido de mulheres submetidas a histerectomia: uma contribuição da enfermagem para a integralidade da assistência ginecológica. Esc. Anna Nery. 2008; 12(4): 637-44.

19. Veiga KCG, Menezes TMO. Produção do conhecimento em enfermagem: a (in) visibilidade da atenção à saúde do idoso. Rev. esc. enferm. USP. 2008; 42(4): 761-8.

20. Silva V, Holzmann APF, Versiani CC, Figueiredo MFS, Lima ACAS, Vieira MA, et al. Análise dos trabalhos de conclusão de curso da graduação em enfermagem da UNIMONTES. Rev. Eletr. Enf. [Internet]. 2009 [cited 2009 jul 30];11(1): 133-43. Available from: http://www.fen.ufg. br/ revista/v11/n1/v11nla17.htm

Artigo recebido em 20.05 .08

Aprovado para publicação em 14.05.09.

Artigo publicado em 30.09.09. 